\title{
The Influence of French on Vocabulary Knowledge of Arabic-speaking University students learning English as a Foreign Language: A Melting Pot
}

\author{
Adela Talbi Hassani ${ }^{1}$ \\ ${ }^{1}$ University of Algiers 2, Algeria
}

\begin{tabular}{|c|c|}
\hline Artic & Abstract \\
\hline$\overline{\text { Artic }}$ & xtent to which background \\
\hline 020 & knowledge of the French language could influence English vocabulary \\
\hline & learning among EFL university students in Algeria. More specifically, the \\
\hline & $\begin{array}{l}\text { possible cross-linguistic influence in this context was researched in relation } \\
\text { to the growth pattern of the receptive written vocabulary size across the }\end{array}$ \\
\hline Key & three years of the undergraduate course. \\
\hline $\begin{array}{l}\text { Vocabulary Size, Cross } \\
\text { linguistic Influence, EFL } \\
\text { (English as a Foreign }\end{array}$ & $\begin{array}{l}\text { Methodology: A cross-sectional research design was used for a total } \\
\text { number of } 184 \text { EFL Algerian university students. The written receptive } \\
\text { vocabulary size was measured using Nation's Vocabulary Size Test (2007) }\end{array}$ \\
\hline ognates & $\begin{array}{l}\text { which contained many words with similar orthographic forms as their } \\
\text { French equivalents. A comparison between the results of the whole }\end{array}$ \\
\hline Paper Type : & $\begin{array}{l}\text { population made it possible to establish the progressive growth pattern from } \\
\text { Year } 1 \text { to Year } 3 \text { of the degree course. }\end{array}$ \\
\hline Resea & $\begin{array}{l}\text { Results: Besides a moderate increase of vocabulary size from one } \\
\text { proficiency level to the other, and an expected decrease pattern of }\end{array}$ \\
\hline Corre & $\begin{array}{l}\text { knowledge from the most frequent English words to the least frequent ones, } \\
\text { the positive cross-linguistic influence of French cognates was highly }\end{array}$ \\
\hline Adela Talbi I & $\begin{array}{l}\text { significant as it led to the knowledge of words that were beyond the expected } \\
\text { level of most participants. }\end{array}$ \\
\hline $\begin{array}{l}\text { Email: } \\
\text { adelaia@yaho }\end{array}$ & $\begin{array}{l}\text { Conclusion/Implication: The facilitative effect of French cognates for EFL } \\
\text { learners in Algerian universities is, therefore, an area that instructors and } \\
\text { syllabus designers can make use of to maximize the vocabulary learning } \\
\text { process. }\end{array}$ \\
\hline
\end{tabular}

1. Introduction

Learning a language that is different from one's mother tongue is one of the most cognitively challenging ventures for most people, and learning the vocabulary of that language is perhaps the most crucial and demanding aspect if the purpose is to become proficient in this language (Meara 1995; Schmitt 2000; Nation 2001; Milton 2009). Indeed, learning and processing a language in any Second/Foreign language (SL/FL) context is primarily based on knowledge of its lexicon. A situation in which one is unable to find the words to express oneself or to understand orally or in writing what others try to transmit is probably one of the most frustrating experiences for a speaker of another language. Given the necessity for any SL/FL students to develop large lexical knowledge to communicate adequately, their vocabulary growth patterns are an area that should concern anyone interested in the learning process. 
Students, instructors, researchers and material designers need to know whether students are gaining enough vocabulary as they progress in their language studies. This sort of information can help better planning and evaluation of language curricula and can lead to a possible adjustment of the learning/teaching methodologies.

Moreover, it is also important to diagnose the difficulties that might hinder this growth pattern, as well as the elements of language learning that can best serve this vocabulary development. For instance, in multilingual environments in which the EFL learner has lexical background knowledge in other languages, the influence of one language over the other can play a role in the target language (TL) learning process. It is generally acknowledged that the similarity between the languages already known by the students and the TL does make vocabulary learning easier, especially when the two languages are typologically similar and have resembling orthographic or auditory forms (Meara\& Buxton, 1987; Meara\& Jones, 1990; Meara, 1993; Fraser, 1999; Kellerman, 1983; Odlin, 1989; Ringbom, 1987).

This element of cross-linguistic influence and its impact on vocabulary development is the focus of the present paper. In Algeria, the linguistic environment is a "melting pot" in which a variety of languages interfere, either as mother tongues (Arabic and Tamazight) or as the first foreign language in the country (French). Thus, for Algerian students learning English as a second foreign language, the presence of this linguistic variety in their prior knowledge certainly plays a role in the way they learn the English language in general and English vocabulary in particular. We assume that among this "melting pot", French has probably the most facilitative influence given its typological closeness with the English language.

\section{Literature Review}

Language transfer is considered an important aspect of Second Language Acquisition theory. However, defining the processes involved in this phenomenon has long been a source of debate among researchers; even the terminology used was different. For instance, this process was referred to as "Language mixing" (Kellerman 1983), "linguistic interference" (Ringbom, 1987), "language transfer" (Kellerman 1983; Odlin 1989), or "cross-linguistic influence" (Kellerman \&Sharwood, 1986). Nowadays in the literature, the terms "transfer" and "crosslinguistic influence" are used frequently and interchangeably to refer to this phenomenon.

Language transfer can be defined as the "influence resulting from similarities and differences between a target language and any other language that has been previously (and perhaps imperfectly) acquired" (Odlin, 1989, p. 27). This influence can have an impact on the way the newly learned language is recognized, interpreted, processed, stored, and produced (Jarvis, 2009). In other words, this means that prior knowledge of a learner, in any language he already knows, will somehow influence his comprehension and production of the target language. This influence can be facilitative in the TL learning process when the language system that is being learned has similarities with other language/s that the learner already knows. While in some other cases, the interaction between the TL and previously learned languages can have a negative hindering effect and lead to errors (Odlin, 2003). 
In the past few decades, more extensive research has been undertaken to explore different factors which might impact language transfer like learner's age, gender, proficiency level, and the learning context. Moreover, the extent and variation of language transfer at various levels of language knowledge such as phonology, syntax, morphology, semantics, pragmatics, sociolinguistics, and lexis have been widely researched (Jarvis \&Pavlenko, 2008). It becomes clear that language transfer is a complex process that can take place at various subsystems of the language. Lexical transfer is believed to be the most relevant aspect of cross-linguistic influence between languages of European origins given that words are more visible and diversified than other language components such as grammatical structures (Ringbom, 1987). Lexical transfer occurs when the learner's vocabulary knowledge in his L1 influences his comprehension, acquisition, and production of words in the target language (Jarvis \&Pavlenko, 2008). When learning a second language, lexical transfer from the mother tongue is believed to be an important cognitive process (Ringbom, 2006). This processing is particularly relevant for beginner learners for whom L1 is the only linguistic reference in terms of vocabulary. In this case, learners try to find relationships between the lexical items of both languages to find equivalence. Their vocabulary acquisition in L2 can also be influenced by the hypotheses they might make on the basis of their knowledge of their L1. In this respect, such linguistic processing can be viewed as a learning strategy that contributes to second language acquisition (Murphy, 2003). This strategic tool of lexical transfer from L1 to L2 is consciously or unconsciously used when the learner has no or incomplete knowledge of L2 words, or when he encounters a communicative situation that is cognitively demanding (Manchon, 2001). That is; when producing TL, lack of vocabulary knowledge can lead to use of transfer from L1 as a compensatory strategy to overcome communication breakdown. This phenomenon has long been labeled as a transfer of knowledge from one language to the other, it has long been perceived as an unintentional mechanism that happens when learning a new language (Jarvis \&Pavlenko, 2008). However, this perception has evolved with time and it became clear that this transfer can also be an intentional strategy that learners consciously apply to achieve their learning purpose.

A major aspect that is mentioned in the literature to affect lexical transfer is related to the language itself, i.e., the typology of the first and second languages. The closeness and distance in lexical forms between the language/s already known by the learner and the TL can determine the degree of difficulty and the speed in learning words of a new language. According to Kellerman $(1977,1983)$, the extent to which a learner would use transfer while learning a TL depends on the way he perceives the closeness or distance between the TL and his mother tongue. His perception of similarities, combined with his incomplete knowledge of some aspects of the TL, would lead him to hypothesize the possible transferability from L1 to L2. Odlin (1989) illustrated this aspect with the example of the words "justifier" in French and "justify" in English. He stated that the similarity in the morphological and phonological form of these words makes their comprehension and memorization much easier for a native English speaker learning French.

One of the most important learner-centered factors reported in the literature to determine when language transfer occurs is the proficiency level of the learner. It is commonly assumed 
that strategies involvinglanguage transfer are used at the early stages of TL learning, and while the learner moves to upper proficiency levels, this crosslinguistic influence decreases (Ringbom, 2007; Odlin, 1989). In his various studies undertaken in relation to comprehension and production of TL, Ringbom viewed lexical transfer as a remedial way to overcome gaps and lack of lexical or syntactic knowledge in the target language learning process. As such, the fact that low proficiency in the TL affects the use of transfer is believed to result more frequently in negative transfer, i.e., errors among low proficiency learners, while such instances tend to be less noted as proficiency increases (Ringbom1987). Thus, lexical transfer is a strategy used to compensate for the lack of lexical knowledge in the TL (Murphy 2003).

Lexical transfer at lower proficiency levels is said to count mainly on the formal characteristics of the words, and the extent to which they are similar or different in the two languages. However, this surface transfer is thought to be more meaning-based when the learner becomes more proficient in the TL as his strategic competence, as well as knowledge of not only the form but also the use of different words in different contexts, would have developed (Ringbom, 2007). This is quite logical as one would assume that the more proficient a learner gets in TL, the larger and deeper his vocabulary knowledge would become, and therefore he would be able to develop his comprehension and production of the TL without necessarily borrowing or transferring words from his mother tongue to overcome communicative breakdowns.

Research on cross-linguistic influence or language transfer in FL learning was initially concerned with the way native language knowledge impacts the L2 learning process. However, there was a rising interest in the study of this transfer in multilingual environments, looking at it from the perspective of the influence that learners' other non-native languages might have on each other, i.e., "lateral transfer" (Odlin, 2003; Jarvis \&Pavlenko, 2008). Therefore, it is realized that the way a learner acquires a new language can be impacted by not only his mother tongue but also by his knowledge of any other language (Ringbom, 1987). It is only since the 1990s that research in the field of Third Language Acquisition (TLA) started to expand as a distinct discipline and separate from SLA.

In the context of TLA, the learner is in contact with three or more languages - each with its system - among which he needs to adapt to meet various communicative settings. Therefore, this context is believed to be more complex than in SLA in which he approaches the TL learning process differently having only the mother tongue as a reference. Despite this complexity, knowledge of more than two languages is seen as a source of many useful and facilitative cues offered by the different languages already known to achieve good comprehension and production in the TL (Ringbom, 2007).

Learners of more than two languages might have a more developed understanding, sensitivity and awareness of different language systems than SL learners for whom L1 is the only source of information. (Thomas, 1988). This linguistic diversity is seen by Thomas (1988) as a possible advantage that helps during the process of learning a new language, and that TLA students tend to achieve better than SLA students. Besides, some studies that investigated cross-linguistic influence in the context of speakers of more than one language noted that 
those learners tend to count on their knowledge in a second language (L2) - rather than their L1 - especially when the L2 is typologically connected to the new language being learned (L3) (Ringbom, 1987; Cenoz 2003). Cenoz (2003) gave the example of someone learning English or French and whose mother tongue is a non-Indo-European language. He believed that this learner would use his lexical knowledge of other Indo-European languages he knows because of their closeness to the TL, instead of using his L1.

This latter context would apply to the Algerian environment of the present study in which Arabic is the L1 of the learners (and also Tamazight for some of them), French is their L2 and English is their L3. The phenomenon of cross-linguistic influence is, therefore, relevant in this linguistically diversified "melting pot", and findings of the present study are believed to contribute to the literature, as this phenomenon has not been extensively researched among Arabic-speaking students, having previous knowledge of French, and learning English as a foreign language.

\section{Methodology and Procedures}

\section{Setting:}

Algeria is a country in which standard Arabic is the first official language (since independence) and Tamazight is the second official language (since 2010) spoken in many regions. Despite the official Arabic discourse, there has always been the social and cultural influence of other languages. If standard Arabic is the formal language used in the economic, social, political, and educational fields, Algerians do not use it in their everyday exchanges. Indeed, Algerian Arabic (also called dialectal Arabic) is what most people use; it contains some Berber and French words as well as other languages that have influenced the Algerian society over the past centuries such as some Turkish, Spanish, Italian, and Maltese words.

Moreover, without being the official language, French is present and used in many official fields such as education, administration and management. An important rate of media also use the French language (radios and TV programs, magazines), and about half of the press is printed in French and is widely distributed. In fact, without being a member of the International Organisation of Francophone Countries, Algeria is considered as having one of the highest rates of French speakers in the world. The strong presence of the French language is not applicable to the official fields only, but it is also used in everyday life by many people of different ages, living mostly in large cities.

In the educational system, the French language was established as the first foreign language of the country in 2004, and as such, it started to be taught as early as primary school; children carry on having French classes during all the years of middle and high school. In higher education, many scientific and technical fields are still being taught in French, even though all the students arrive from high school with a heavy Arabic educational background. Thus, within this linguistic melting-pot, it is clear that there is more than one linguistic influence when it comes to vocabulary learning. This is what the present paper attempts to investigate, 
with a particular focus on the relationship between French and English languages and how a possible cross-linguistic influence could impact the growth of vocabulary size.

\section{Participants:}

This study was undertaken with an overall group of 184 university students enrolled in the English Department of the University of Algiers 2. In this university, English is taught through an LMD program (LMD standing for Licence-Master-Doctorate). The focus in this study was on the first cycle of the undergraduate course (Licence) covered by the first three academic years. Four sample groups were involved:

- Newly enrolled students (low-intermediate)

- 1st Year students (pre-intermediate)

- 2nd Year students (intermediate)

- 3rd Year students (advanced)

\section{Research instruments:}

A demographic information questionnaire was given to the participants as a first stage to collect some useful background information and have an overall picture of their profile and experience with language learning. Besides age, gender, year of study, and a number of years studying EFL, they were also asked to specify their native language by choosing between Arabic, Tamazight, or French). However, they also could mention any other language they have learned or are learning. The aim of asking them about their mother or other tongue(s) was to find out about their linguistic background and its possible influence on English learning.

One of the goals of this study is to measure the written receptive vocabulary knowledge and growth of EFL students across three years. The Vocabulary Size Test designed by Nation (2007) was used for that purpose (the 14000-item version A). This test comprises 140 multiple-choice questions related to lexical items taken from the British National Corpus (Bauer \& Nation, 1993). This version of the test is believed to assess the knowledge of the first 14,000 words, graded from the high-frequently to the low-frequently used words in English. As testing subjects on all 14,000 words of this corpus was practically impossible, Nation's VST seemed more convenient because it tests knowledge of only 10 lexical items from each 1000 word family level; these 10 words reliably represent most of the other words contained in each family level. As such, to obtain the overall receptive vocabulary size of the participants, the scores of the VST need to be multiplied by 100 .

For each lexical item, the students had to choose the definition of the word that seemed the best to them from a list of four choices. The tested words appeared in short simple sentences that did not provide a lot of contexts. Nation's purpose of de-contextualizing the lexical items is to ensure that the VST assesses exclusively knowledge of the word itself without the influence of contextual clues. However, the short sentence containing the tested word does provide the participants with information about the part of speech of the target word. The 
stems in which the tested words appear contain vocabulary that is within the first 500 words of English, i.e., words that are much easier than the tested word itself.

The 140 items of the test were presented in order of frequency, starting from the most frequently used words in English $(1 \mathrm{~K})$ - the first 1000 word families - until the least frequently used ones (14K) - meaning 14,000-word families. Even if the participants were required to answer all 140 lexical items, the scores of each band are expected to decrease gradually as they got to the low-frequency words. The overall calculated score of the test is thus assumed to reflect the written receptive vocabulary size of the test-taker. The choice of this VST was believed to fit the purpose of the present study, as it contains several words that have similar orthographic forms with French words. Thus while testing the vocabulary size of the population, the possible cross-linguistic influence of French lexical background knowledge was also researched.

\section{Procedure:}

Despite the difference in the proficiency level of the four sample groups, all of them took the same VST testing on knowledge of all 14,000-word families, i.e., 14K. Unlike other vocabulary measurement tools which select only a few word bands of frequencies to adjust to the proficiency levels of the test-takers, the VST assesses participants' knowledge of all frequency bands, including the ones that can be considered beyond their knowledge level. The reason behind this choice is the belief that participants can know the vocabulary that is higher than their expected proficiency level if the word resembles a mother tongue cognate, or if the word belongs to an area that is of special interest to the participant or relates to one of his hobbies (Nation 2007). Moreover, the high-frequency word bands such as $1 \mathrm{~K}$ and $2 \mathrm{~K}$ were also taken into consideration; it was felt important to include even the first bands of the test to give the participants the benefit of doubt and assess their real vocabulary size score instead of just assuming what they might know.

In the Algerian context, the diversity and richness of the linguistic background of these participants, expected to share knowledge of Arabic, French and Tamazight, was thought to provide them with the possibility of knowing words beyond their proficiency level. For instance, whatever the level of the participants, they were assumed to have a minimum knowledge of French vocabulary. The fact is that French and English languages have many cognates that are alike in their written form; this aspect was reflected in the present VST as many written forms of words, even in the low-frequency levels, looked like their French equivalents. Here are a few examples:

"gauche","limpid" (14K)

"atoll", "communique", "jovial" (13K)

"caffeine", "refectory" (12K)

"aperitif" (11K)

"authentic", "cabaret", "eclipse”, "palette” $(8 \mathrm{~K})$

"olives", "demography" (7K)

"cavalier" (6K)

"cube", "fracture" (5K) 
Such words would be easy to guess for someone knowing French, even though they belong to low-frequency bands that only very advanced learners of English are expected to know. There are also words in the VST that are borrowed from Arabic, such as "emir" (11K), even though it is also a noun used in French.

Nation advised against the removal of any lexical items for which the test-takers might have equivalent L1 cognates, as such removal would certainly change the overall measurement tool. He explains that "loanwords" are natural parts of any linguistic profile, arguing that the VST aims at measuring "words known rather than words learnt" (Nation 2007).

\section{Results and Discussion}

When asked to identify their mother tongue(s), most participants mentioned Arabic as their first language. However, as shown in Table 1, they also stated French and Tamazight as being part of their linguistic background, with lower rates though. Even though Arabic is consciously considered as the L1 for most participants, we assume that the influence of French in their subconscious is much higher than what they declared. This assumption would possibly be checked in the results of the vocabulary size test below, in which many lowfrequency words have the same stems as their French equivalents.

Table 1 Participants' background information

\begin{tabular}{|c|c|c|c|c|}
\hline Year of study & $\begin{array}{c}\text { Newly enrolled } \\
\text { (Low-intermediate) }\end{array}$ & $\begin{array}{c}\text { 1stYear } \\
\text { (Pre-intermediate) }\end{array}$ & $\begin{array}{c}\text { 2nd Year } \\
\text { (Intermediate) }\end{array}$ & $\begin{array}{c}\text { 3rd Year } \\
\text { (Advanced) }\end{array}$ \\
\hline Number & 30 & 81 & 37 & 36 \\
\hline Gender & $\begin{array}{c}\text { Male: } 5 \\
\text { Female: } 25\end{array}$ & $\begin{array}{c}\text { Male: } 17 \\
\text { Female:64 }\end{array}$ & $\begin{array}{c}\text { Male: } 6 \\
\text { Female:31 }\end{array}$ & $\begin{array}{c}\text { Male: } 1 \\
\text { Female: } 35\end{array}$ \\
\hline Average Age & 18.8 & 19.8 & 20.5 & 21.9 \\
\hline Native Language & $\begin{array}{c}\text { Arabic: } 90 \% \\
\text { French: 13\% } \\
\text { Tamazight: 3\% }\end{array}$ & $\begin{array}{c}\text { Arabic: } 79 \% \\
\text { French: } 8 \%\end{array}$ & $\begin{array}{c}\text { Arabic: } 94 \% \\
\text { French: } 5 \%\end{array}$ & $\begin{array}{c}\text { Arabic: } 97 \% \\
\text { Tamazight: } 19 \%\end{array}$ \\
Tamazight: $2 \%$
\end{tabular}

Source: Author

After completing the Demographic Information Questionnaire, all the participants were required to fill in the Vocabulary Size Test.As shown in Table 2, the average overall vocabulary size of the participants jumped from 5924 words by the time they joined the university to 7500 words just before they graduated. With a difference of 1576 words over three years of study, one can deduce that the average gains in vocabulary knowledge are about 525 words per year. However, when looking at the gains from one proficiency level to the other, one can notice that the growth varies considerably. Indeed, the gains that the participants achieved from the time they joined the university - before any university instruction took place - and the time they were about to finish their first year is 486 words; this might reflect the impact of the first-year instruction of the LMD curriculum. During this 
first year, teaching is mainly based on language and skills courses such as Reading/Writing, Listening/Speaking, Phonetics, Grammar, etc. Taking the author's teaching experience as a reference, the purpose of the first year is generally to provide the students with the appropriate language tools that would serve as a basis for the following years of the course. Nevertheless, the difference in vocabulary size between Year 1 and Year 2 is significantly higher, with a gain of 833 words. Given that the data collection took place at the end of the academic year, just before the final examinations, this gain of 833 words is supposed to reflect the influence of the second year teaching that the participants had on their vocabulary size. The content of the second year is a mix between language skills and content courses, with a majority of content courses that aim to broaden students' knowledge and provide them with a variety of sources of input. The participants, however, seemed to have gained much less vocabulary during their final year of instruction, with a difference of only 257 words from Year 2 to Year 3. The last year of the degree course is exclusively content-based and the students at that stage are supposed to have developed autonomy to enable them to acquire knowledge - including lexical knowledge - independently and much more effectively than in the previous years especially that many of them would become future EFL instructors. Thus, this drop in lexical gains is quite surprising at this last stage of the degree course.

Table 2 Vocabulary Size Test scores for the four sample groups (Comparison)

\begin{tabular}{|c|c|c|c|c|c|c|c|c|c|c|c|c|c|c|c|c|}
\hline & \multicolumn{14}{|c|}{ Vocabulary Frequency Levels } & \multirow{2}{*}{$\begin{array}{l}\text { Total } \\
\text { Average } \\
\text { Score }\end{array}$} & \multirow[b]{2}{*}{$\begin{array}{l}\text { Gains } \\
\text { per } \\
\text { year }\end{array}$} \\
\hline & $1 \mathrm{~K}$ & $2 \mathrm{~K}$ & $3 \mathrm{~K}$ & $4 \mathrm{~K}$ & $5 \mathrm{~K}$ & $6 \mathrm{~K}$ & $7 \mathrm{~K}$ & $8 \mathrm{~K}$ & $9 \mathrm{~K}$ & $10 \mathrm{~K}$ & $11 \mathrm{~K}$ & $12 \mathrm{~K}$ & $13 \mathrm{~K}$ & $14 \mathrm{~K}$ & & \\
\hline $\begin{array}{l}\text { Newly } \\
\text { enrolled }\end{array}$ & 7,90 & 6,03 & 4,90 & 5,21 & 4,72 & 4,69 & 4,17 & 4,59 & 2,76 & 3,14 & 4.00 & 2,76 & 2,14 & 2,24 & 59,24 & ----- \\
\hline $\begin{array}{c}\text { 1st } \\
\text { Year }\end{array}$ & 7,69 & 6,10 & 5,20 & 5,83 & 4,96 & 4,86 & 4,60 & 5,33 & 3,33 & 3,25 & 4,54 & 3,15 & 2,77 & 2,48 & 64,10 & 486 \\
\hline $\begin{array}{l}\text { 2nd } \\
\text { Year }\end{array}$ & 8,46 & 6,30 & 5,78 & 6,05 & 6,32 & 5,95 & 5,24 & 5,84 & 4,16 & 3,76 & 4,95 & 3,89 & 3,11 & 2,62 & 72,43 & 833 \\
\hline $\begin{array}{l}\text { 3rd } \\
\text { Year }\end{array}$ & 8,25 & 7,06 & 5,78 & 6,58 & 6,11 & 5,64 & 4,89 & 6,31 & 4,39 & 3,64 & 5,64 & 3,94 & 3,31 & 3,47 & 75,00 & 257 \\
\hline
\end{tabular}

Source: Author

Looking at the results per frequency levels in Table 2, it is realized thatthe results follow a logical but moderate increase as the participants moved from one year to the other, except for the 2nd Year students who performed slightly better than 3rd year students in some frequency bands. Moreover, the decreasing pattern from $1 \mathrm{~K}$ to $14 \mathrm{~K}$ was more or less identical in the four sample groups, and this is particularly obvious in figure 1. 


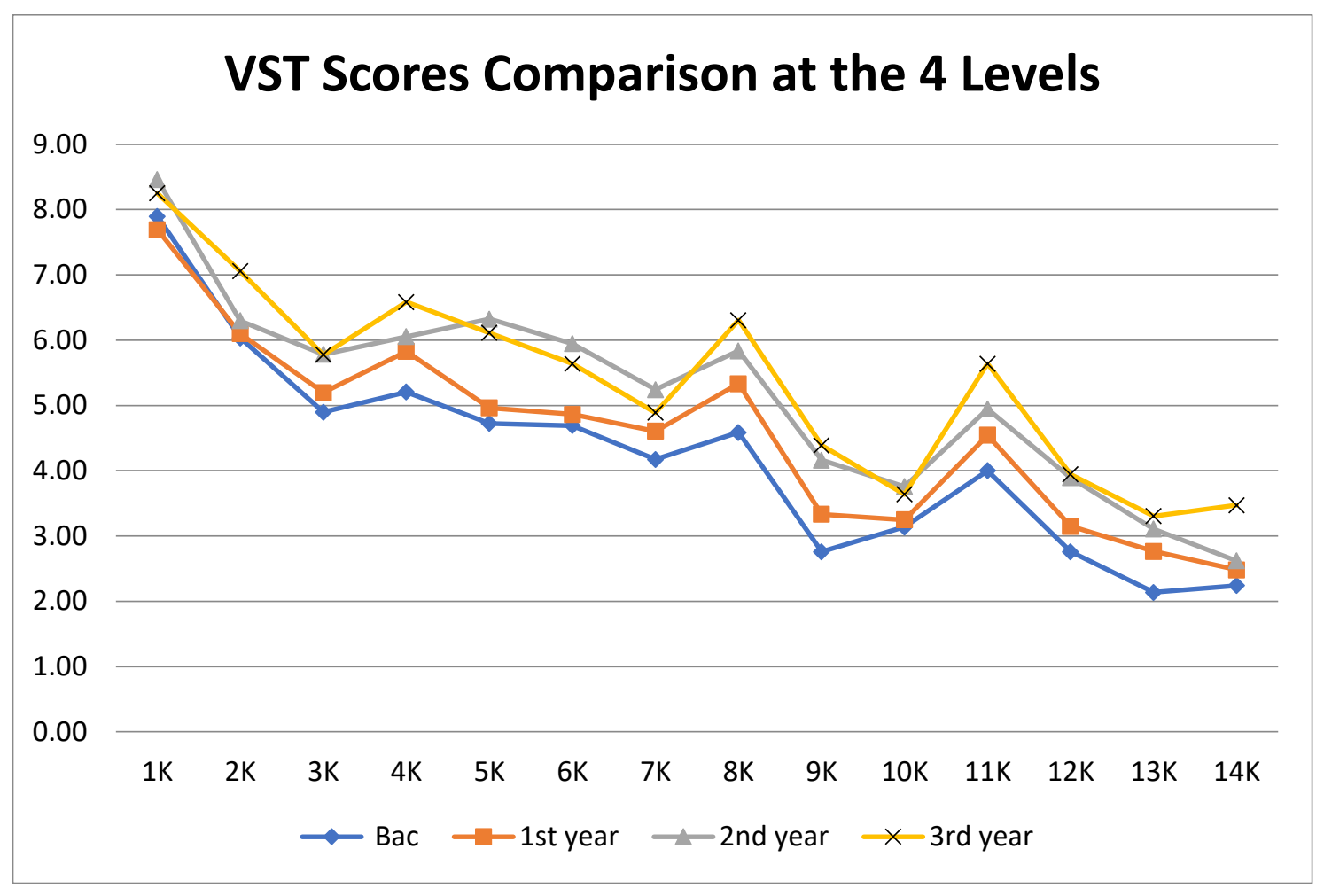

Figure 1Comparison of VST scores in terms of the 14 frequency bands

The average scores decreased gradually as the participants went from the highest to the lowest frequency bands, with an average of 7.89 out of ten for $1 \mathrm{~K}$ items as the highest score, to an average of 2.14 out of 10 for $13 \mathrm{~K}$ as the lowest score. In other words, the vocabulary knowledge of most participants seemed to logically decrease when tested from the most frequent words in English $(1 \mathrm{~K})$ to the least frequent words in English $(14 \mathrm{~K})$, sustaining the assumption that the acquisition of vocabulary by EFL students is gradual and follows the frequency pattern of words (Schmitt 1994, Read 1988, Schmitt \& Clapham 2001, Milton 2009).

However, throughout the decreasing curve, there were two peaks of $8 \mathrm{~K}$ and $11 \mathrm{~K}$, during which the participants seemed to have performed better than previous frequency bands. The $8 \mathrm{~K}$ and $11 \mathrm{~K}$ bands contain words that are not frequently encountered and used in the English language. However, the participants in the experiment were able to identify the meaning of some of these lexical items even though the latter were expected to be beyond their proficiency level. These peaks were particularly unexpected for the low-intermediate sample (BAC) who scored no less than 4.5 out of 10 in $8 \mathrm{~K}$ and 3.96 in $11 \mathrm{~K}$. These scores increased slightly among the other proficiency levels until the advanced group scored $6.31(8 \mathrm{~K})$ and $5.64(11 \mathrm{~K})$.

As expected, this phenomenon might be because there were many words in these two bands that had to resemble written forms with their French equivalents. Indeed, words like palette $(8 \mathrm{~K})$, eclipse $(8 \mathrm{~K})$, authentic $(8 \mathrm{~K})$, cabaret $(8 \mathrm{~K})$, yoga $(11 \mathrm{~K})$, puma $(11 \mathrm{~K})$, aperitif $(11 \mathrm{~K})$ could possibly be guessed by the participants because they have similar orthographic form and thus similar cognates in the French language. Knowing French is widely used in Algeria, 
and that it is the first foreign language taught in the educational system from primary school(to university, in many faculties), it is not surprising to find the high influence of this language on the VST scores of the participants of the present study. Moreover, they could also guess the meaning of a word like Emir $(11 \mathrm{~K})$ maybe because it is used in the French language as well as borrowed from Arabic, the native language of almost all the participants. This finding supports Schema Theory according to which concepts can be meaningful only when they are related to something the subject already knows. That is to say, when a new language experience - including vocabulary - is encountered, it is understood only if it can be related to an existing schema and simultaneously become part of it. Thus, the comprehension of a text is considered to rely much on the schematic knowledge of the reader/listener who makes assumptions about the information he is exposed to (Anderson, 1980). The participants, whatever their proficiency level, who performed well at these frequency bands were probably able to understand the meaning of these French-like words because they already had the schema of these words in French, and therefore were using their crosslinguistic knowledge to decode the meaning of these words. According to a large number of studies (Meara\& Buxton, 1987; Meara\& Jones, 1990; Manchon, 2001, Odlin 2003, Murphy 2003, Jarvis \&Pavlenko 2008, Jarvis 2009), having similar or resembling orthographic or semantic cognates in an already known language (L1 or L2) is likely to make the learning of these words in the TL much easier. In his study with French-speaking learners of English, Fraser (1999) found out that the vocabulary retention rate of the participants was in average $50 \%$ thanks to the use of L1-related identification clues to infer the meaning of words while reading. It is clear that $\mathrm{L} 1$ cognates make reading comprehension more accessible and vocabulary learning easier in the target language only when the L1 and L2 of a learner belong to the same language family (Meara, 1993), which is the case for English and French as both belong to two families of the same Indo-European language. The present findings are therefore aligned with other studies that advocated the facilitative effect of language transfer in vocabulary learning and comprehension when the languages are typologically similar (Kellerman,1983; Odlin, 1989; Ringbom, 1987), and more specifically with the studies that shed light on the fact that knowledge of French facilitates learning of English (Cenoz, 2003). Moreover, the present findings confirm that all frequency levels of the Vocabulary Size Test should be taken (Nguyen \&Nation, 2011), instead of assuming that students do not know the meaning of words that are beyond their supposed proficiency level and, therefore, possibly underestimate their vocabulary size. In this respect, these findings confirm that the use of the VST was appropriate for the participants of the present study.

It is true that in the context of the present study, Arabic and Tamazight are the L1 of most participants, but French is also an important background language for many Algerians as it is the first foreign language of the country and is widely present in many aspects of everyday life. Therefore, when considering vocabulary learning in a TL, one cannot ignore the facilitative effect of the native language or any other additional language because the possible typological similarities or differences can make a difference in terms of difficulty or ease of the vocabulary acquisition process, especially at a visual level, when these words have similar spellings. 


\section{Conclusion and Suggestion}

The present study aimed at investigating the phenomenon of cross-linguistic influence in the linguistically diversified context of Algeria, as well as its relationship with the growth of vocabulary size among EFL undergraduate students. Employing a test measuring the written receptive vocabulary size at each proficiency level, and a comparison among the whole population, we could establish the growth pattern of vocabulary size in general as well as the cross-linguistic influence of French over English vocabulary learning in particular. The results of the study indicate that most of the participants were able to recognize the meaning of some low-frequency words that were beyond their expected proficiency level because these words had similar orthographic forms as their French equivalents which is not their L1, but it has a "special status" of L1 for many speakers. Indeed, because French is the first foreign language in Algeria with a significant influence on most aspects of life, the students already had cognates about these words. There is no doubt that cognates are a useful source for rapid vocabulary acquisition and development in language learning. Therefore, the facilitating effect of French cognates can be an area that instructors and syllabus designers can make use of to adjust and maximize the vocabulary learning process, as raising learners' awareness of morphological, phonological and structural similarities or differences between languages can facilitate the recognition of cognates and consequently lead to easier lexical learning. Cognate-based instruction can positively encourage learners to pay attention to cognates - something they may not do consciously - and would therefore lead to better lexical learning (Molnar). By raising learners' awareness about the morphological forms of words, instructors can help Algerian EFL students to identify the similarities and differences between French and English vocabulary, and would trigger their prior knowledge in a more effective way. These are some instances of techniques that can be used by teachers in the language skills courses to make the most of the similarities between English and French, for instance, in a way that can assist better vocabulary learning.

It is important to mention that in the present study the Vocabulary Size Test written format was used and the participants were required to read the words and find their meanings, thus the visualization of the English words which spell-like French might have helped trigger the students' cross-linguistic knowledge. However, this process would have possibly been different if these English words were pronounced orally, granted the complexity of the French sound-spelling system. Studies investigating the possible transfer from French to English or vice-versa by EFL students at the level of listening or speaking /pronunciation skills, would provide insightful information about this cross-linguistic phenomenon in relation to vocabulary learning and its impact on vocabulary teaching. When it comes to language learning in general, the linguistic richness or "the melting pot" in any given society should be positively exploited by all means whenever possible.

\section{Acknowledgments}

The Ph.D. work from which the present paper is extracted has been conducted under the supervision of Professor Faiza Bensemmane from the University of Algiers 2, Algeria. 


\section{Conflict of Interest}

The author declares no conflict of interest.

\section{Funding}

The study was not funded by any institution/ university.

Data

The data of this study were taken from the Ph.D. work of the author (ongoing); they represent only one aspect extracted from the overall research work.

\section{References}

Anderson, J.R (1980) Cognitive Psychology and Its Implications. San Francisco: Freeeman.

Bauer, L. \& Nation, P. (1993). Word families. International Journal of Lexicography, 6 (4), 253-279.

Cenoz, J. (2003). The role of typology in the organization of the multilingual lexicon. In The multilingual lexicon (pp. 103-116). Springer, Dordrecht.

Fraser, C. A. (1999). Lexical processing strategy use and vocabulary learning through reading. Studies in Second Language Acquisition, 21(2),225-241.

Hancin-Bhatt, B. and W. Nagy. (1994). Lexical transfer and second language morphological development. Applied Psycholinguistics, 15(3),289-310.

Jarvis, S. and Pavlenko, A. (2008). Crosslinguistic Influence in Language and Cognition. New York and London: Routledge.

Jarvis, S. (2009). Lexical transfer. The bilingual mental lexicon: Interdisciplinary approaches, 99, 124.

Kellerman, E. (1977). Towards a characterization of the strategy of transfer in second language learning. Interlanguage Studies Bulletin, 2, 58-145.

Kellerman, E. (1983). Now you see it, now you don't. In S. Gass\& L. Selinker (Eds.), Language transfer in language learning (pp. 112-134). Rowley, MA: Newbury House

Kellerman, E \&Sharwood Smith, M (eds) (1986). Crosslinguistic Influence in Second Language Acquisition. Oxford, UK: Pergamon.

Manchon, R. M. (2001). Trends in the Conceptualizations of Trends in the second language composing strategies: A critical Analysis. International Journal of English Studies, 1(2), 47-70.

Meara, P. (1993). The bilingual lexicon and the teaching of vocabulary. In R. Schreuder\& B. Weltens (Eds.), The Bilingual Lexicon (pp: 279-298). Philadelphia: John Benjamins.

Meara, P. (1995). The importance of an early emphasis on L2 vocabulary. JALT, 19: 8-11.

Meara, P. \& Buxton, B. (1987). An alternative to multiple choice vocabulary tests. Language Testing, 4,142-51.

Meara, P. and Jones, G. (1990). Eurocentres Vocabulary Size Test, version E1.1/K10. Zurich: Eurocentres Learning Service. 
Molnar, T. (2010). Cognate recognition and L3 vocabulary acquisition. ActaUniversitatis Sapientiae, Philologica, 2(2),337-49.

Milton, J. (2009). Measuring second language vocabulary acquisition. Bristol, UK: Multilingual Matters.

Murphy, S. (2003). Second language transfer during third language acquisition. Columbia University Working Papers in TESOL \& Applied Linguistics, 3(1), 1-21.

Nation, P. (2001). Learning Vocabulary in Another Language. Cambridge: CUP

Nation, I. S. P. (2007). The four strands. Innovation in Language Learning and Teaching. 1(1): $1-12$.

Nation, P. (2012). The Vocabulary Size Test. Retrieved from https://www.wgtn.ac.nz/lals/resources/paul-nations-resources/vocabulary-tests/thevocabulary-size-test/Vocabulary-Size-Test-information-and-specifications.pdf

Nguyen, L. T. C., \& Nation, P. (2011). A bilingual vocabulary size test of English for Vietnamese learners. RELC Journal, 42(1),86-99

Odlin, T. (1989). Language transfer: Cross-linguistic influence in language learning. Cambridge: Cambridge University Press.

Odlin, T. (2003). Cross-linguistic influence. In C. Doughty \& M. H. Long (Eds.), The handbook of second language acquisition (pp. 436-486). Malden, MA: Blackwell.

Read, J. (1988). Measuring the vocabulary knowledge of second language learners. RELC Journal, 19(2),12-25.

Ringbom, H. (1987). The role of first language in foreign language acquisition. Clevedon: Multilingual Matters.

Ringbom, H. (2006). Cross-linguistic Similarity in Foreign Language Learning. Clevedon: Multilingual Matters.

Ringbom, H. (2007). The importance of cross-linguistic similarity in foreign language learning: Comprehension, learning and production. Clevedon: Multilingual Matters.

Schmitt, N. (1994). Vocabulary testing: Questions for test development with six examples of tests of vocabulary size and depth. Thai TESOL Bulletin, 6(2),9-16.

Schmitt, N. (2000). Vocabulary acquisition. In N, Schmitt (ed). Vocabulary in Language Teaching, ed. N. Schmitt, (pp:116-41). Cambridge: Cambridge Language Education.

Schmitt, N., Schmitt, D., \& Clapham, C. (2001). Developing and exploring the behaviour of two new versions of the Vocabulary Levels Test. Language Testing, 18(1),55-88

Thomas J. 1988. 'The role played by metalinguistic awareness in second and third language learning'. Journal of Multilingual and Multicultural Development 9(3),235-46. https://doi.org/10.1080/01434632.1988.9994334 